\title{
Extreme food refusal resulting in pellagra in a toddler living in the "maize belt" of Sri Lanka
}

\author{
Manouri P Senanayake ${ }^{1}$, Ranmali Rodrigo $^{2}$ \\ Sri Lanka Journal of Child Health, 2013: 41(3): 166-167
}

(Key words: Pellagra; food refusal; maize)

\section{Introduction}

Pellagra (niacin deficiency) is encountered only under extreme conditions when the diet has niacin of low bio-availability. Maize (corn) where niacin is in a bound (glycosylated) form is such a food ${ }^{1}$. Pellagra is very rare in Sri Lanka and was not encountered even among war-affected children ${ }^{2}$. We report a toddler who ate only boiled maize due to extreme food fussiness and developed pellagra.

\section{Case report}

A 23 month old firstborn daughter of nonconsanguineous parents presented with persistent watery, occasionally bloody, diarrhoea of 5 months duration, without an infective cause identified at 3 hospital admissions. Aversion to sun exposure was reported. This was demonstrated by covering of eyes and crying when exposed to sunlight. Her developmental milestones had regressed globally over the past 3 months. An erythematous peeling rash had appeared around neck and upper chest at 22 months. There was no family history of similar illness or childhood deaths. Parents were educated up to grade 10; mother, a former nurse-aide and father, an electrician, both appeared healthy. Exclusive breast feeding until complementary foods were introduced at seven months was reported but she had been a "very poor eater" from the outset. Diverse foods were met with crying and refusal. Growth curve flattened from eleven months and although health professionals provided advice on nutritive value of foods no help or guidance on feeding techniques were offered. Breast feeding continued and the only solid food accepted was boiled mashed maize. Formula milk, commercially available weaning foods or vitamin supplements were never administered. There was no history of treatment for tuberculosis or seizures. Immunizations were up to date.

${ }^{1}$ Professor in Paediatrics, Department of
Paediatrics, Faculty of Medicine, Colombo,
${ }^{2}$ Registrar in Paediatrics, University Paediatric
Unit, Lady Ridgway Hospital for Children,
Colombo

(Received on 19 October 2012: Accepted on 21 December 2012)
On examination, she was irritable and disinterested in the surroundings. Skin showed well demarcated, hyper-pigmented, peeling areas with a red base, placed symmetrically over forearms, upper chest and neck, resembling Casal's necklace. Tongue was erythematous and conjunctiva was pale. There was no oedema or hepatomegaly. Hair was thin but not depigmented. $\mathrm{Z}$ scores for weight and length (for age) were -2.33 and -1.32 respectively. Only abnormality on systems examination was bilateral coarse crepitations in lungs. Ability to walk unaided, scribble, point to objects were lost and speech had regressed from 20 meaningful single words to four.

Investigations found moderate anaemia $(\mathrm{Hb}$ $9.5 \mathrm{~g} / \mathrm{dl}$ ), microcytic erythrocytes, normal serum albumin, transaminases and creatinine. Urine was free of protein and urinary amino-acidogram was within normal limits. Stools contained reducing substances. Stool electrolytes were normal and bacterial culture and viral studies found no pathogens. HIV antibodies were absent and CD4 counts were normal. A clinical diagnosis of pellagra was made. Nicotinic acid (200mg daily), other multivitamins including vitamin B complex, a high-calorie, high-protein diet and intravenous cefotaxime for the respiratory tract infection, were commenced.

A week later she became febrile, tachypnoeic, tachycardic with hepatomegaly $(2.5 \mathrm{~cm}$ below costal margin), and mild oedema. Cardiac failure and worsening broncho-pneumonia were diagnosed. Chest radiograph confirmed changes of broncho-pneumonia and cardiac failure. Echocardiogram showed trivial tricuspid regurgitation and small pericardial effusion. Blood culture was negative. Urine grew a coliform $\left(10^{5} \mathrm{org} / \mathrm{ml}\right)$ sensitive to meropenem. Despite treatment for cardiac failure, intravenous meropenem, albumin infusion and nicotinic acid, cardiac failure, oedema and hypoalbuminaemia aggravated. Skin and hair changes of kwashiorkor were absent. Serum transaminases and electrolytes remained normal. She succumbed after two weeks, to cardiac failure complicating severe bronchopneumonia. Post-mortem found pneumonic changes in both lungs without histological or microbiological evidence of tuberculosis and 
pericardial effusion that was not purulent. Histopathology showed marked atrophy of intestinal villi in both small and large intestines. No carcinoid tumour was present.

\section{Discussion}

Pellagra is rare because niacin and its precursor tryptophan are present in a variety of food (fleshfood, pulses, groundnut, vegetables, fruits). However, pellagra is known on diet restricted to foods low in niacin or requiring special methods of preparation for release of this micronutrient. Niacin, nicotinic acid and nicotinamide are essential as components of co-enzymes in numerous metabolic pathways. Deficiency results in pellagra, a disease of "3Ds"- dermatitis, diarrhoea and developmental delay, all of which this child with classical 'Casal's necklace' had. Seldom used confirmatory tests of low urinary N1methylnicotinamide (N1-MN) and 2-pyridone were unavailable $^{3}$. The fourth ' $\mathrm{D}$ ' - death - occurred despite specific and supportive care ${ }^{3}$.

Hartnup disease is associated with pellagra-like dermatosis but was ruled out by absence of gross aminoaciduria ${ }^{4}$. Secondary causes of niacin deficiency i.e. carcinoid tumour or cirrhosis and clinical features of kwashiorkor were absent. Hepatomegaly was secondary to dilated cardiomyopathy and cardiac failure, both recognised complications of pellagra ${ }^{5}$.

Aggravation of diarrhoea and hypoalbuminaemia may have been due to re-feeding. It was not due to niacin toxicity which is reported with sustained release forms and much higher doses. Features of overdosing (flushing and liver failure) were absent ${ }^{6}$. Breast milk niacin levels are proportionate to maternal blood levels but we did not investigate the mother who had no features of pellagra, ${ }^{7,8}$.

The child lived in the South-east quadrant of Sri Lanka described as the "maize belt" of the country $^{8}$. Maize was a frequent household food item, eaten directly off the cob or as flour. Both preparation methods do not release bound niacin.

This case demonstrates that even when food and basic health services are available food fads can cause dangerous micronutrient deficiency and that provision of nutritional advice should include guidance on feeding practices as well, in situation of eating disorders.

\section{Acknowledgements}

We thank Prof. Jayamini Seneviratne, Consultant Dermatologist, Dr. Eresha Jasinghe Consultant Chemical Pathologist (both of Lady Ridgeway
Children's Hospital) and Dr Nishali Ekanayake, Consultant Histopathologist, Medical Research Institute, Colombo for their assistance.

\section{References}

1. Gregory III JF. Nutritional properties and significance of vitamin glycosides. Annual Review of Nutrition 1998; 18:277-96. http://dx.doi.org/10.1146/annurev.nutr.18.1.277

2. Jayatissa R. Rapid assessment of nutritional status among displaced population in Vavuniya: Medical Research Institute (Colombo); 2010. [Accessed 2012 July 14]. Available from: http://www.hpsl.1k/Files/Surveys/LKS0005 A ssessment $\% 20$ Vavuniya $\% 20$ March.pdf

3. Hegyi J, Schwartz RA, Hegyi V. Pellagra: Dermatitis, dementia, and diarrhoea. International Journal of Dermatology 2004; 43: $1-5$.

http://dx.doi.org/10.1111/j.13654632.2004.019 $\underline{59 . x}$

4. Wilken B, Yu JS, Brown DA. Natural history of Hartnup disease. Archives of Disease in Childhood 1977; 52: 38-40. http://dx.doi.org/10.1136/adc.52.1.38

5. Venugopalan P, Agarwal AK, Worthing EA. Chronic cardiac failure in children due to dilated cardiomyopathy: diagnostic approach, pathophysiology and management. European Journal of Pediatrics 2000; 159:803-10. http://dx.doi.org/10.1007/s004310000588

6. Guyton JR, Bays HE. Safety considerations with niacin therapy. The American Journal of Cardiology 2007; 99: S22-S31. http://dx.doi.org/10.1016/j.amjcard.2006.11.018

7. Lawrence RA, Lawrence RM. Breastfeeding: A guide for the medical profession. 7th ed. Maryland Heights, Missouri: Mosby, Elsevier; 2011

8. Ranaweera NFC, de Silva GAC, Fernando MHJP, Hindagala HB. Maize production in Sri Lanka: Regional Co-ordination Centre for Research and Development of Coarse Grains, Pulses, Roots and Tuber Crops in the Humid Tropics of Asia and the Pacific; 1988. 